\title{
The Effect of Dietary Saccharoculture on Growth Performance, Non-Specific Immunity and Autochthonous Gut Microbiota of Gibel Carp Carassius
} auratus

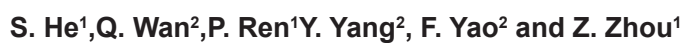 \\ ${ }^{1}$ Key Laboratory for Feed Biotechnology of the Ministry of Agriculture, Feed Research Institute, Chinese Academy of Agricultural Sciences, Beijing 100081, P. R. China \\ ${ }^{2}$ Science of Animal and Technology College, Anhui Agricultural University, Hefei 230036, P. R. China
}

\begin{abstract}
The objective of this study was to evaluate the effect of a commercial fermented yeast product (Saccharoculture, Veterinary Pharmaceuticals, Korea), on the growth performance, non-specific immunity and autochthonous intestinal microbiota of gibel carp Carassius auratus. Following an eight week feeding trial the growth performance and serum non-specific immunity of fish fed one of four treatments (A: control group, B: $2 \mathrm{~g} / \mathrm{kg}$ Saccharoculture, C: $3 \mathrm{~g} / \mathrm{kg}$ Saccharoculture or D: $2 \mathrm{~g} / \mathrm{kg}$ Saccharoculture $+0.1 \mathrm{~g} / \mathrm{kg}$ flavomycin) was measured. Additionally, the predominant autochthonous intestinal microbiota was analyzed by denaturing gradient gel electrophoresis (DGGE). The results indicated that dietary supplementation of Saccharoculture or Saccharoculture combined with flavomycin significantly improved final weight, weight gain (WG), special growth rate (SGR) and feed conversion ratio (FCR) compared to the control group $(P<0.05)$, and the best growth performance was obtained in group B. However, the non-specific immunity factors were not significantly affected by dietary yeast or flavomycin $(P>0.05)$. Compared to the control group, fish fed dietary yeast exhibited modulated intestinal bacterial communities. Levels of some bacteria were elevated by dietary Saccharoculture, such as, Acinetobacter sp. (FR749840.1, FJ646641.1), Escherichia vulneris (HQ259947.1) and Cetobacterium somerae (AB353124.1). Cetobacterium sp. (HM778168.1) and Lactococcus lactis subsp. (EF589778.1) were suppressed in the Saccharoculture with flavomycin group. However, Nevskia sp. (AB426558.1) was suppressed by the higher level Saccharoculture or Saccharoculture and flavomycin combination.
\end{abstract}

Keywords: Fermented yeast product; Gibel carp; Intestinal microbiota; DGGE

\section{Introduction}

Dietary supplementation with a variety of products containing yeast (Saccahromyces cerevisiae) has been evaluated in a number of different fish species [1-4]. It has been observed that fermented yeast products can positively influence growth performance [1,2,4], as well as the non-specific immune responses, such as lysozyme and complement activity $[1,3,4]$. The efficacy of yeast maybe contributed to its various immune stimulating compounds such as $\beta$-glucans, nucleic acids, mannan oligosaccharides (MOS) and other cell wall components [5].

The gibel carp (Carassius auratus) is an important fish species in China, because of its excellent taste and rapid growth [6]. The fish intestinal microflora has been implicated as playing several functions in respect to nutritional digestion, defending against pathogens and enhancing immunity [7-9]. However, there is no information on the effects of dietary yeast on the intestinal microbiota of gibel carp. Also in China, antibiotic growth promoters such as flavomycin are widely used to improve production to satisfy the growing demand for aquaculture products [4]. To the best of our knowledge, no information is available on the effects of yeast supplementation or yeast combined with flavomycin on gibel carp. Thus the present study was conducted to compare the effect of dietary Saccharoculture and a Saccharoculture and flavomycin combination on growth parameters, non-specific immunity and intestinal microbiota of gibel carp.

\section{Methods}

\section{Experimental diets}

The basal diet formulation and proximate composition are shown in Table 1; the chemical composition was analyzed according to AOAC methods [10]. The basal formulation served as the control diet and three experimental diets were produced by supplementing the basal formulation with yeast and flavomycin, as shown in Table 2. The yeast product, Saccharoculture, was supplied by Veterinary Pharmaceuticals, Korea; the level of probiotic Saccharomyces cerevisiae J8734 is ca. $1.5 \times 10^{10} \mathrm{CFU}$ per kilogram of Saccharoculture. The diets were extruded to obtain pellets (2-3 $\mathrm{mm}$ diameter), then were dried using an electrical fan at room temperature and stored at $4^{\circ} \mathrm{C}$ until feeding.

\section{Husbandry conditions}

Gibel carp were obtained from a fish farm in Hefei city, Anhui, P.R. China. Fish were acclimated to laboratory conditions for 15 days in a $1000 \mathrm{~L}$ plastic tank and fed a basal diet twice a day during the period. The feeding trial was carried out in a recirculation system consisting of 20 flat bottom fiberglass tanks $(60 \mathrm{~cm} \times 60 \mathrm{~cm} \times 60 \mathrm{~cm}$, effective water volume $180 \mathrm{~L}$ ). Tanks were connected to a central processing system

*Corresponding authors: Z. Zhou, Key Laboratory for Feed Biotechnology of the Ministry of Agriculture, Feed Research Institute, Chinese Academy of Agricultural Sciences, No.12 Zhongguancun South Street, Beijing 100081, P. R. China, Tel: +86 10 82106053; Fax: +86 10 82106054; E-mail: zhou_zg@msn.com

Y. Yang, Science of Animal and Technology College, Anhui Agricultural University, Hefei 230036, P. R. China, E-mail: yangyanou@ahau.edu.cn

Received August 02, 2011; Accepted October 15, 2011; Published October 25, 2011

Citation: He S, Wan Q,Ren P, Yang Y, Yao F, et al. (2011) The Effect of Dietary Saccharoculture on Growth Performance, Non-Specific Immunity and Autochthonous Gut Microbiota of Gibel Carp Carassius auratus. J Aquac Res Development S1:010. doi:10.4172/2155-9546.S1-010

Copyright: @ $2011 \mathrm{He} \mathrm{S}$, et al. This is an open-access article distributed under the terms of the Creative Commons Attribution License, which permits unrestricted use, distribution, and reproduction in any medium, provided the original author and source are credited. 
Citation: He S,Wan Q,Ren P, Yang Y, Yao F, et al. (2011) The Effect of Dietary Saccharoculture on Growth Performance, Non-Specific Immunity and Autochthonous Gut Microbiota of Gibel Carp Carassius auratus. J Aquac Res Development S1:010. doi:10.4172/2155-9546.S1-010

Page 2 of 6

\begin{tabular}{ll}
\hline Ingredients & $\%$ (dry weight) \\
\hline White fishmeal & 48.45 \\
Wheat & 38.40 \\
Soybean oil & 4.00 \\
Vitamin C & 0.11 \\
Vitamin Premix ${ }^{1}$ & 0.39 \\
Mineral Premix ${ }^{2}$ & 4.50 \\
Choline chloride & 0.15 \\
a- starch & 4.00 \\
Chemical composition & \\
Dry matter(\%) & 91.46 \\
Crude protein (\% dry matter) & 36.84 \\
Crude lipid (\% dry matter) & 8.38 \\
Ash (\% dry matter) & 13.84 \\
Gross energy (J/mg) & 17.20 \\
\hline
\end{tabular}

${ }^{1}$ Vitamin premix (g/100g): vitamin A,550 I.U.; vitamin D3, 100 I.U.; vitamin E,5 I.U.; vitamin $\mathrm{K}, 1$; niacin, 10; riboflavin, 2; pyridoxine, 2; thiamin, 2; D-calcium pantothenate, 5; biotin, 0.01; folacin, 0.5; vitamin B12, 2; ascorbic acid, 10; inositol, 10.

${ }^{2}$ Mineral Premix (g/100g): NaCl, $1 ; \mathrm{MgSO}_{4} .7 \mathrm{H}_{2} \mathrm{O}, 15 ; \mathrm{NaH}_{2} \mathrm{PO}_{4} .2 \mathrm{H}_{2} \mathrm{O}, 25 ; \mathrm{KH}$ $2 \mathrm{PO}_{4}$, 32; $\mathrm{Ca}\left(\mathrm{H}_{2} \mathrm{PO}_{4}\right)_{2} \mathrm{H}_{2} \mathrm{O}, 20 ; \mathrm{FeC}_{6} \mathrm{H}_{5} \mathrm{O}_{7} .5 \mathrm{H}_{2} \mathrm{O}, 2.5 ; \mathrm{C}_{6} \mathrm{H}_{10} \mathrm{CaO}_{6} .5 \mathrm{H}_{2} \mathrm{O}, 3.5$ $\mathrm{ZnSO}_{4} .7 \mathrm{H}_{2} \mathrm{O}, 0.353 ; \mathrm{MnSO}_{4} .4 \mathrm{H}_{2} \mathrm{O}, 0.162 ; \mathrm{CuSO}_{4} .5 \mathrm{H}_{2} \mathrm{O}, 0.031 ; \mathrm{CoCl}_{2} .6 \mathrm{H}_{2} \mathrm{O}$ $0.001 ; \mathrm{KIO}_{3}, 0.003$; Cellulose, 0.45 .

Table 1: Feed formulation and chemical composition of the basal diet used in the experiment.

\begin{tabular}{llll}
\hline Diet & Basal diet & Saccharoculture $^{1}$ & ${\text { Flavomycin } 8 \%^{2}}^{2}$ \\
\hline A & 100 & & \\
B & 99.8 & 0.2 & \\
C & 99.7 & 0.3 & \\
D & 99.7 & 0.2 & 0.01 \\
\hline
\end{tabular}

'supplied by Veterinary Pharmaceuticals, Korea

${ }^{2}$ supplied by Xiangweisi Ltd, Shangdong, China

Table 2: The experimental group and diet formulation (\%).

with column clinoptilolite filter (volume, $1500 \mathrm{~L}$ ) for water treatment. Clinoptilolite is a natural zeolite with a strong adsorption capacity for ammonia. Aeration was provided intermittently for 3 min per $15 \mathrm{~min}$. Dissolved oxygen was maintained above $6.00 \mathrm{mg} / \mathrm{L}$, ammonia below $0.20 \mathrm{mg} / \mathrm{L}$ and temperature at $25 \pm 0.5^{\circ} \mathrm{C}$. The illumination was provided by fluorescent lamps from 8:30 to 20:00.

\section{Experimental design}

Prior to the beginning of the experiment, the fish were starved for one day, and 460 fish were selected, batch-weighed and allocated into each of the twenty tanks (23 fish per tank). Each experimental diet had four replicate tanks. During the experiment, the fish were fed to satiation twice a day (at 9:00 and 16:00).

\section{Growth measurements}

The trial lasted for 56 days. At the end of the trial, fish were weighed after one day of food deprivation, and five fish from each tank were randomly sampled to measure body length, body height, body width, viscera and hepatopancreas weights. Growth performance, feed utilization, viscerosomatic index and slaughter index were calculated according to the following formulate:

Weight gain $(\mathrm{WG})=100 \times(\mathrm{FBW}-\mathrm{IBW}) / \mathrm{IBW}$;

Special growth rate $(\mathrm{SGR})=100 \times \ln (\mathrm{FBW} / \mathrm{IBW}) / \mathrm{t}$;

Feed conversion rate $(\mathrm{FCR})=\mathrm{IT}_{\mathrm{d}}(\mathrm{g}) / \mathrm{WG}(\mathrm{g})$;

Condition factor $(\mathrm{BI})=$ bodyweight $(\mathrm{mg}) /$ [body length $(\mathrm{cm}) \times$ body height $(\mathrm{cm}) \times$ body width $(\mathrm{cm})$ ];
Slaughter index $(\mathrm{SI})=100 \times$ body weight without viscera $(\mathrm{g}) /$ body weight $(\mathrm{g})$;

Viscerosomatic index $(\mathrm{VSI})=100 \times$ viscera weight $(\mathrm{g}) /$ body weight (g);

Where IBW is the initial body weight of fish, FBW is the final body weight of fish, $t$ is the experimental period (56 days) and $\mathrm{IT}_{d}$ is the total dry diet consumption during the experimental period.

\section{Non-specific immunological analysis}

After the termination of the feeding trial, three fish from each tank were sampled for blood. Blood was taken from caudal vein by hypodermic syringe, and blood was left at $4{ }^{\circ} \mathrm{C}$ overnight, then centrifuged at $3000 \mathrm{~g}$ for $10 \mathrm{~min}$, and isolated sera was stored frozen at $-20^{\circ} \mathrm{C}$ for subsequent analysis of lysozyme (LSZ), complement 3 (C3) and complement 4 (C4) activity. Serum LSZ activity, the activity of serum C3 and C4 were measured according to He et al. [4].

\section{Intestinal predominant microbiota analysis}

Five fish from each tank were randomly sampled at the end of the feeding trial. The intestinal tracts were sampled and processed as described elsewhere [11]. To avoid individual variation, the sampled intestinal walls from each tank were homogeneously mixed together $[9,11,12]$. The total genomic DNA was extracted with CTAB and lysozyme methods [4] and purified with a Tiangen DNA purification kit (Tiangen Biotechnologies, Beijing, China).

The V3 region of the 16S rRNA gene was amplified according to Liu et al. [12]. DGGE of PCR products was performed with the BioRad Dcode ${ }^{\mathrm{TM}}$ mutation detection system (Bio-Rad, Hercules, CA, USA) according to $[4,11,12]$. To identify the inserted sequences, the BLAST 2.0 algorithm was used to compare the derived sequence to 16S rRNA sequences in the DNA Data Bank of Japan (DDBJ) database. Species identification was made on the basis of percentage similarity to database sequences (98.0-100.0\% similarity).

\section{Statistical analysis}

Data are expressed as mean values \pm S.D. The effects of diet on immune parameters and growth performance were analyzed by oneway analysis of variance (ANOVA) using statistical analysis software (SAS) (Cary, NC, USA). In our study, a similarity coefficient (Cs) matrix less than 0.60 is regarded as significant difference; while $0.60<\mathrm{Cs}<0.85$ is marginal difference and Cs $>0.85$ is very similar [4].

\section{Results}

\section{Growth performance}

The growth performance of carp after the $56 \mathrm{~d}$ experiment is shown in Table 3. The weight gain (WG) and final body weight (FBW) of carp in groups B ( $2 \mathrm{~g} / \mathrm{kg}$ Saccharoculture) and D ( $2 \mathrm{~g} / \mathrm{kg}$ Saccharoculture + $0.1 \mathrm{~g} / \mathrm{kg}$ flavomycin) were significantly higher than the control group and group $\mathrm{C}(P<0.05)$; the highest level appeared in group $\mathrm{B}$. The higher level of dietary Saccharoculture (Group C) did not significantly affect WG or FBW compared to the control group $(P>0.05)$. Specific growth rate (SGR) was significantly affected by the dietary fermented yeast product (Table $3, P<0.05$ ), except for group $C$. The highest SGR was obtained in group $\mathrm{B}$ and then $\mathrm{D}$, both of which were significantly higher than the control group and group $\mathrm{C}(P<0.05)$.

The condition factor (BI) of fish in group B and D were significantly 
Citation: He S,Wan Q,Ren P, Yang Y, Yao F, et al. (2011) The Effect of Dietary Saccharoculture on Growth Performance, Non-Specific Immunity and Autochthonous Gut Microbiota of Gibel Carp Carassius auratus. J Aquac Res Development S1:010. doi:10.4172/2155-9546.S1-010

Page 3 of 6

\begin{tabular}{lllll}
\hline Parameters & A & B & C & D \\
\hline IBW(g) & $7.55 \pm 0.06$ & $7.55 \pm 0.06$ & $7.45 \pm 0.13$ & $7.63 \pm 0.15$ \\
FBW(g) & $28.12 \pm 1.08^{\mathrm{a}}$ & $33.55 \pm 0.71^{\mathrm{b}}$ & $29.08 \pm 0.39^{\mathrm{a}}$ & $32.29 \pm 1.04^{\mathrm{b}}$ \\
WG (\%) & $271.2 \pm 14.95^{\mathrm{a}}$ & $344.4 \pm 11.34^{\mathrm{b}}$ & $290.4 \pm 8.77^{\mathrm{a}}$ & $323.4 \pm 17.00^{\mathrm{b}}$ \\
SGR (\%/d) & $2.34 \pm 0.07^{\mathrm{a}}$ & $2.66 \pm 0.05^{\mathrm{b}}$ & $2.38 \pm 0.07^{\mathrm{a}}$ & $2.58 \pm 0.07^{\mathrm{b}}$ \\
FCR & $1.62 \pm 0.07^{\mathrm{a}}$ & $1.49 \pm 0.05^{\mathrm{b}}$ & $1.53 \pm 0.05^{\mathrm{ab}}$ & $1.50 \pm 0.06^{\mathrm{b}}$
\end{tabular}

* Superscripts showed the result of multiple range test (Duncan's procedure), different letters showed significant differences $(P<0.05)$.

IBW, initial body weight; FBW, final body weight; WG, weight gain; SGR, special growth ratio; FCR, feed conversion ratio.

Table 3: Effects of experimental diets on the growth and diet utilization of gibel carp Carassius auratus*

\begin{tabular}{llll}
\hline Diet & $\mathrm{BI}(\mathrm{mg} / \mathrm{cm} 3)$ & $\mathrm{SI}(\%)$ & VSI $(\%)$ \\
\hline A & $456.3 \pm 12.51^{\mathrm{a}}$ & $89.02 \pm 1.55$ & $4.22 \pm 0.15$ \\
B & $483.2 \pm 11.94^{\mathrm{b}}$ & $89.10 \pm 1.44$ & $3.98 \pm 0.22$ \\
C & $445.8 \pm 17.45^{\mathrm{a}}$ & $90.15 \pm 1.05$ & $3.74 \pm 0.32$ \\
D & $479.6 \pm 10.29^{\mathrm{b}}$ & $89.50 \pm 1.27$ & $3.76 \pm 0.28$ \\
\hline
\end{tabular}

* Superscripts showed the result of multiple range test (Duncan's procedure). Different letters showed significant differences $(P<0.05)$.

Table 4: Effects of experimental diets on the condition factor (BI), slaughter index (SI) and viscerosomatic index (VSI) of gibel carp Carassius auratus*.

higher $(P<0.05)$ than groups $\mathrm{A}$ and $\mathrm{C}$. There was no significant difference in SI and VSI among the treatments $(P>0.05)$.

\section{Non-specific immunity}

The effect of dietary supplementation of fermented yeast product on serum lysozyme activity (LSZ) and complement activity (C3 and C4) is presented in Table 5. Statistical analysis of data showed that there were no significantly differences of LSZ, C3 and C4 activity for all groups $(P>0.05)$, but Saccharoculture slightly increased to a certain extent the content of $\mathrm{C} 3$, although not significantly.

\section{Intestinal predominant microbiota}

The microbial communities of fish intestines were analyzed after the 8 week feeding trial (Figure 1); a similarity coefficient (Cs) was used to calculate pairwise comparisons of the DGGE fingerprint profiles (Figure 2). There were marginal difference in the intestinal microflora structure induced by dietary Saccharoculture $(\mathrm{Cs}=0.77)$. The microbiota of group B ( $2 \mathrm{~g} / \mathrm{kg}$ Saccharoculture) and group C (3 g/kg Saccharoculture) were very similar $(\mathrm{Cs}=0.85)$. However, when dietary Saccharoculture and flavomycin were combined together, the effect was marginally strengthened $(\mathrm{Cs}=0.76)$ beyond Saccharoculture alone. The phyla identified by sequencing were Fusobacteria, Firmicutes, Proteobacteria and Unclassified bacteria (Table 6). Some Acinetobacter sp. (ca. 25\%) and Lactococcus lactis subsp. (EF589778.1) (ca. 15\%) were the predominant strains among intestinal bacteria. Some bacteria, such as Cronobacter dublinensis (HQ880412.1) were only present in the dietary Saccharoculture supplemented groups (in the absence of flavomycin), while Yersinia kristensenii (HM142713.1) was only detected in the higher level dietary Saccharoculture group (group C). Dietary Saccharoculture could also enhance the amount of Acinetobacter sp. (FR749840.1), Acinetobacter sp. (FJ646641.1), Escherichia vulneris (HQ259947.1) and Cetobacterium somerae, but these bacteria were suppressed with the use of flavomycin. However, Nevskia sp. (AB426558.1) was suppressed by higher level Saccharoculture and Saccharoculture and flavomycin combination. Dietary flavomycin also showed a suppressive effect on Lactococcus lactis subsp. (EF589778.1).

\begin{tabular}{llll}
\hline Diet & $\mathrm{LYZ}(\mathrm{U} / \mathrm{ml})$ & $\mathrm{C} 3(\mathrm{~g} / \mathrm{L})$ & $\mathrm{C} 4(\mathrm{~g} / \mathrm{L})$ \\
\hline A & $46.82 \pm 10.23$ & $0.34 \pm 0.04$ & $0.25 \pm 0.03$ \\
B & $44.75 \pm 6.54$ & $0.38 \pm 0.07$ & $0.23 \pm 0.03$ \\
C & $46.80 \pm 9.47$ & $0.41 \pm 0.05$ & $0.26 \pm 0.02$ \\
\hline D & $48.76 \pm 7.23$ & $0.38 \pm 0.06$ & $0.22 \pm 0.04$ \\
\hline
\end{tabular}

** Superscripts showed the result of multiple range test (Duncan's procedure). Different letters showed significant differences $(P<0.05)$

Table 5: Effects of experimental diets on the serum lysozyme (LYZ) and compliment (C3 and C4) activity of gibel carp Carassius auratus*

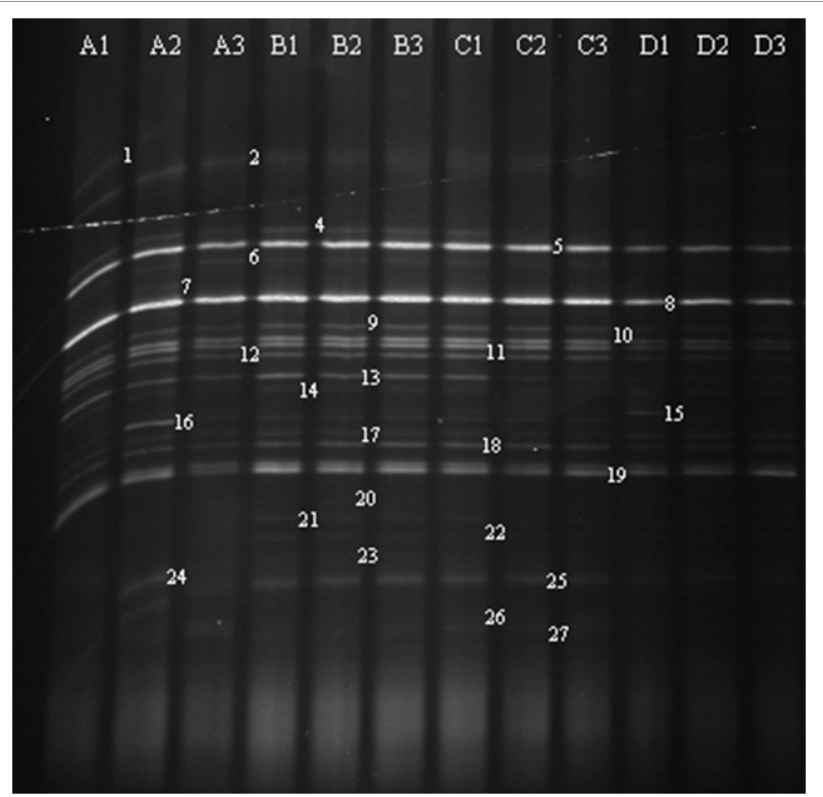

Figure 1: DGGE depicting the effects of the experimental diets on the gut autochthonous bacterial community of gibel carp Carassius auratus.

\section{Discussion}

In the present study, dietary supplementation with yeast had positive effects on gibel carp growth rate, weight gain and SGR compared to the control diet (Table 4). Similar benefits have been reported previously in fish fed dietary yeast $[13,14]$. The beneficial influence of Saccharoculture on growth was possibly due to its high content of nucleic acids, mannan oligosaccharides (MOS), lactose and other cell wall components [15]. Previously it has been reported that Japanese flounder fed a diet supplemented with $5 \mathrm{~g} \mathrm{~kg}^{-1}$ MOS exhibited better weight gain and feed conversion ratio than those fed a control diet [16]. However, in the present study, the growth performance of fish fed $0.3 \%$ Saccharoculture was lower compared to that of fish fed $0.2 \%$ Saccharoculture (Table 4 ). Several reports have suggested that low level dietary inclusion of yeast products could efficiently improve aquatic animal growth parameters; $0.1 \%$ inclusion of brewer's yeast has been reported to elevate the growth performance and feed utilization of Nile tilapia after 9 weeks feeding [2] and $0.25 \%$ baker's yeast has been reported to improve gold fish growth parameters [17]. But even higher levels of dietary commercial brewer's yeast product (2\%) could also exert a positive influence on the growth performance of juvenile beluga [18]. These contradictory results may be attributed to the different fish species and different properties of the yeast products. In the present study, the growth performance was not further strengthened by dietary inclusion of the antibiotic growth promoter flavomycin.

Yeast cells provide about 7.7\% crude glucan [19], and glucans have 
Citation: He S,Wan Q,Ren P, Yang Y, Yao F, et al. (2011) The Effect of Dietary Saccharoculture on Growth Performance, Non-Specific Immunity and Autochthonous Gut Microbiota of Gibel Carp Carassius auratus. J Aquac Res Development S1:010. doi:10.4172/2155-9546.S1-010

Page 4 of 6

\begin{tabular}{|c|c|c|c|c|c|c|c|}
\hline phylum & Band No. & $\begin{array}{l}\text { Closest relative (obtained from BLAST } \\
\text { search) }\end{array}$ & Identity (\%) & A & B & C & $\mathrm{D}$ \\
\hline \multirow[t]{12}{*}{ Proteobacteria } & 1 & Acinetobacter sp. (HQ841068.1) & 100 & $0.8 \pm 1.1$ & 0.0 & 0.0 & $0.9 \pm 0.2$ \\
\hline & 2 & Acinetobacter sp. (EU260174.1) & 99 & $2.2 \pm 0.5$ & $1.1 \pm 0.6$ & $0.9 \pm 0.7$ & $1.4 \pm 0.9$ \\
\hline & 4 & Acinetobacter haemolyticus (HQ132734.1) & 100 & $1.3 \pm 0.3$ & $0.9 \pm 0.2$ & $0.5 \pm 0.2$ & $0.8 \pm 0.5$ \\
\hline & 5 & Acinetobacter sp. (FR749840.1) & 100 & $19.2 \pm 4.7$ & $23.0 \pm 1.7$ & $25.6 \pm 3.2$ & $12.0 \pm 7.3$ \\
\hline & 6 & Acinetobacter sp. (HQ659186.1) & 100 & $1.2 \pm 0.6$ & $0.7 \pm 0.0$ & $0.8 \pm 0.2$ & $0.9 \pm 0.3$ \\
\hline & 9 & Acinetobacter sp. (FJ646641.1) & 99 & $1.2 \pm 0.4$ & $1.9 \pm 0.2$ & $1.5 \pm 0.6$ & $0.8 \pm 0.4$ \\
\hline & 13 & Nevskia sp.(AB426558.1) & 100 & $4.3 \pm 1.2$ & $4.2 \pm 1.0$ & $1.4 \pm 1.0$ & $2.8 \pm 1.5$ \\
\hline & 14 & Escherichia vulneris (HQ259947.1) & 100 & $0.5 \pm 0.2$ & $1.4 \pm 0.8$ & $0.7 \pm 0.3$ & $0.3 \pm 0.1$ \\
\hline & 15 & Shewanella xiamenensis (HQ418493.1) & 100 & 0.0 & 0.0 & 0.0 & $2.6 \pm 1.3$ \\
\hline & 21 & Escherichia fergusonii (HQ259962.1) & 100 & $0.4 \pm 0.3$ & $1.6 \pm 0.8$ & $0.2 \pm 0.2$ & $0.3 \pm 0.1$ \\
\hline & 22 & Cronobacter dublinensis (HQ880412.1) & 100 & 0.0 & $0.7 \pm 0.1$ & $0.2 \pm 0.3$ & 0.0 \\
\hline & 25 & Serratia sp. (HQ588852.1) & 100 & $2.6 \pm 2.7$ & $3.0 \pm 0.7$ & $1.9 \pm 0.6$ & $2.7 \pm 0.1$ \\
\hline \multirow[t]{7}{*}{ Firmicutes } & 10 & $\begin{array}{l}\text { Lactococcus lactis subsp. lactis } \\
\text { (EF589778.1) }\end{array}$ & 100 & $1.6 \pm 0.9$ & $0.7 \pm 0.5$ & $0.6 \pm 0.2$ & $1.3 \pm 0.4$ \\
\hline & 16 & Staphylococcus pasteuri (HQ739095.1) & 100 & $2.4 \pm 2.5$ & $0.6 \pm 0.1$ & $0.4 \pm 0.3$ & $2.5 \pm 0.0$ \\
\hline & 17 & Anoxybacillus sp.(HQ696615.1) & 100 & $0.7 \pm 0.1$ & $0.9 \pm 1.0$ & $0.3 \pm 0.2$ & $0.4 \pm 0.3$ \\
\hline & 19 & Lactococcus lactis subsp. (EF589778.1) & 99 & $13.9 \pm 3.5$ & $17.1 \pm 2.1$ & $11.6 \pm 3.8$ & $8.7 \pm 5.2$ \\
\hline & 24 & Anoxybacillus sp. (FN432807.1) & 100 & $0.9 \pm 1.2$ & 0.0 & 0.0 & $1.0 \pm 0.2$ \\
\hline & 26 & Yersinia kristensenii (HM142713.1) & 100 & 0.0 & 0.0 & $0.8 \pm 0.5$ & 0.0 \\
\hline & 27 & $\begin{array}{l}\text { Lactococcus lactis subsp. cremoris } \\
\text { (JF297369.1) }\end{array}$ & 99 & $0.9 \pm 0.6$ & 0.0 & $2.4 \pm 1.0$ & $0.7 \pm 0.1$ \\
\hline \multirow[t]{2}{*}{ Fusobacteria } & 11 & Cetobacterium sp. (HM778168.1) & 100 & $3.2 \pm 0.3$ & $1.1 \pm 0.3$ & $4.8 \pm 2.1$ & $1.7 \pm 1.5$ \\
\hline & 18 & Cetobacterium somerae (AB353124.1) & 100 & $1.9 \pm 0.4$ & $2.4 \pm 0.4$ & $3.7 \pm 1.3$ & $1.2 \pm 0.7$ \\
\hline \multirow[t]{5}{*}{ Unclassified bacteria } & 7 & Marine sponge bacterium (EU346455.1) & 99 & $0.3 \pm 0.3$ & 0.0 & 0.0 & $0.3 \pm 0.0$ \\
\hline & 8 & Uncultured bacterium (GU485261.1) & 99 & $39.6 \pm 5.6$ & $35.7 \pm 1.5$ & $37.6 \pm 3.8$ & $22.6 \pm 17.0$ \\
\hline & 12 & $\begin{array}{l}\text { Uncultured bacterium clone } 2701 \\
\text { (HM452218.1) }\end{array}$ & 99 & $1.6 \pm 0.7$ & $2.2 \pm 0.3$ & $3.5 \pm 0.9$ & $1.1 \pm 0.5$ \\
\hline & 20 & Activated sludge bacterium (GU136512.1) & 99 & 0.0 & $0.2 \pm 0.2$ & 0.0 & 0.0 \\
\hline & 23 & Bacterium B81(2011) (HQ674993.1) & 99 & 0.0 & $0.4 \pm 0.1$ & $0.3 \pm 0.1$ & 0.0 \\
\hline
\end{tabular}

Table 6: Identity of the gut autochthonous bacterial community of gibel carp Carassius auratus fed experimental diets and the relative abundance (\%)

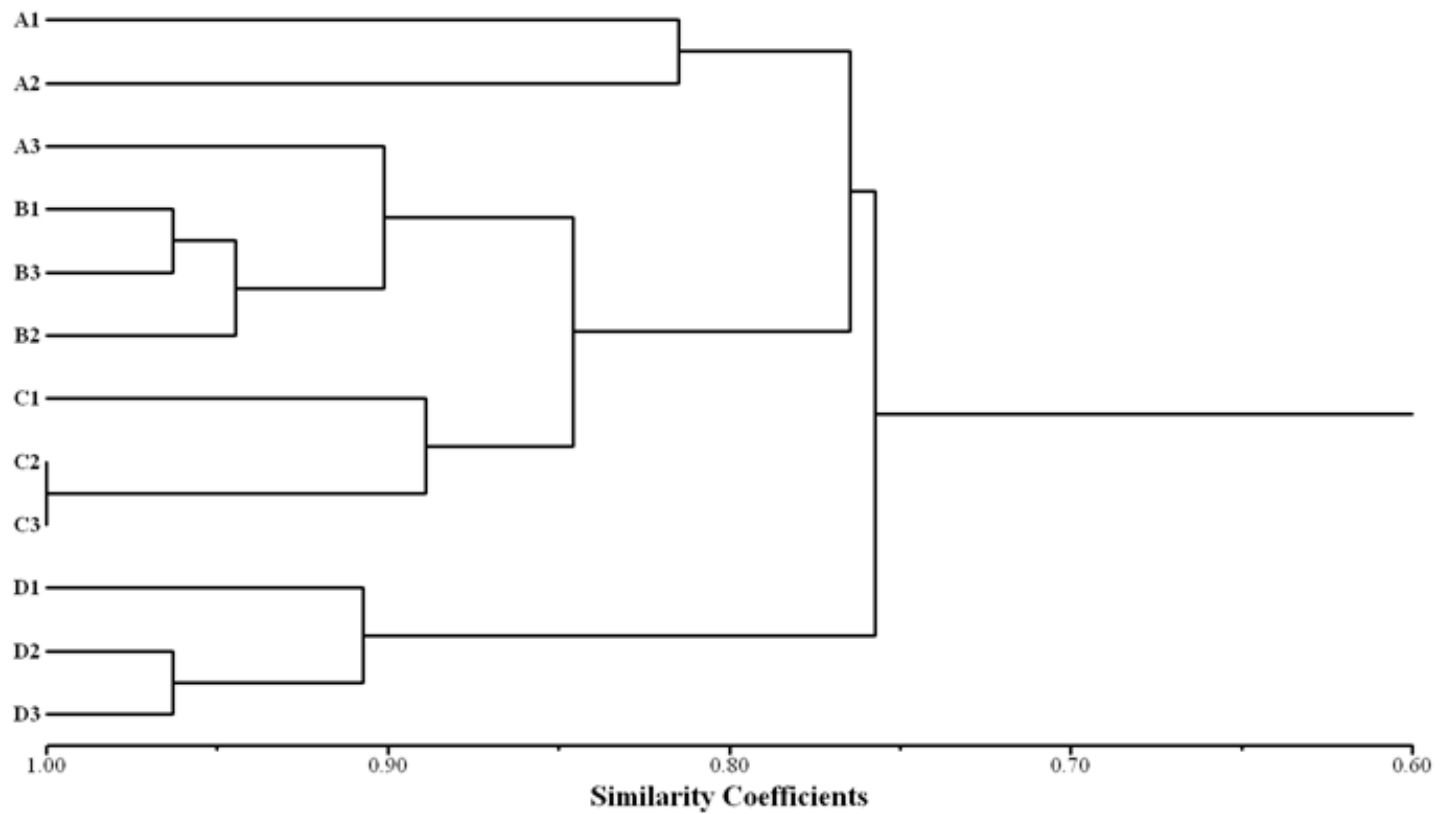

Figure 2: Cluster analysis of the gut autochthonous bacterial communiies from DGGE analysis of gibel carp Carassius auratus fed the experimental diets.

been reported to be capable of enhancing innate immune responses, including respiratory burst of head kidney macrophages, serum complement activity and lysozyme activity [20-22] when administered by injection. However, the increase of serum lysozyme was not observed in fish orally receiving glucans [23], which agrees with the results of the present study. The complement system is an important 
Citation: He S,Wan Q,Ren P, Yang Y, Yao F, et al. (2011) The Effect of Dietary Saccharoculture on Growth Performance, Non-Specific Immunity and Autochthonous Gut Microbiota of Gibel Carp Carassius auratus. J Aquac Res Development S1:010. doi:10.4172/2155-9546.S1-010

Page 5 of 6

element of both the innate and adaptive immune system in fish [2426]. In our study, the $\mathrm{C} 3$ activity was slightly improved by dietary yeast supplementation, but this was not significant at $P<0.05$. These effects have been described by Raa [27] who investigated immunostimulants in both fish and shellfish. The results obtained from recent trout and carp trials show that the serum complement activity of fish fed MOS increases during the investigation period [28].

On comparing the DGGE band patterns in Figure 1, we observed the increasing levels of some bacterium by dietary yeast (Table 6); these include Acinetobacter sp. (FR749840.1), Lactococcus lactis subsp. (EF589778.1), Cetobacterium somerae (AB353124.1), uncultured bacterium clone 2701 (HM452218.1) and Bacterium B81(2011) (HQ674993.1). Acinetobacter sp. is a normal intestinal bacteria of some fish [4,29], in our lab, two species of Acinetobacter were isolated from the gut of hybrid tilapia ( + O. nilotica $\widehat{\partial}$ O. aureas), which could degrade N-Acyl homoserine lactones (AHL) molecules (quorum sensing molecules) produced by Aeromonas hydrophila (data not published). Acinetobacter sp. have also been reported to degrade AHLs from phytopathogenic bacterium Burkholderia [30]. Therefore elevated gut Acinetobacter sp. may provide a level of protection against Gram negative pathogens, but further studies are required to verify this hypothesis. From our sequencing results, several lactic acid bacteria (LAB) were detected in the intestine of carp. LAB have been considered beneficial residents of the fish's intestinal ecosystem by producing bacteriocins and lactic acid, which inhibit growth of certain fish pathogens and thus positively affect the host's microflora [3133]. In the present study, DGGE based analysis of the autochthonous intestinal microbiota revealed that $L$. lactis subsp. (EF589778.1) levels were significantly higher in carp fed $0.2 \%$ dietary Saccharoculture $(P<$ $0.05)$; a similar result has been reported with traditional culture-based method [34]. He et al. [4] showed that a Cetobacterium somerae-like organism was selectively stimulated in the intestine of hybrid tilapia by dietary yeast culture (DVAQUA, USA), which was also observed in our study. Cetobacterium somerae has been reported to be an important intestinal bacterium in fish which contributes towards the host's vitamin B12 requirements [35]. The results of the present study indicate that the Saccharoculture modulates the intestinal microbiota towards a potentially more beneficial microbial community. However it should be noted that the level of two bacteria, Acinetobacter sp. (FR749840.1) and L. lactis subsp. (EF589778.1), were dramatically reduced with the dietary inclusion of flavomycin. The reason may be that flavomycin mainly impaired the transglycolase activities through penicillinbinding proteins [36]. Further studies are required to identify the LAB species or other probiotics affected by dietary yeast in order to ascertain their contributory affect towards the host benefits.

In summary, the results indicate that a diet containing $0.2 \%$ Saccharoculture with or without $0.01 \%$ flavomycin $(8 \%)$ had the most significant growth-promoting effects on gibel carp. Saccharoculture increased the relative abundance of some potentially beneficial bacteria, such as, Lactococcus lactis subsp. lactis (EF589778.1). However, when Saccharoculture and flavomycin were combined together, flavomycin overshadowed the effect of Saccharoculture on the intestinal microbiota. None of the diets tested exerted effects on the immune parameters tested after 8 weeks.

\section{Acknowledgements}

This research was supported by the Research Fund of Veterinary Pharmaceuticals, Korea.

\section{References}

1. Siwicki AK, Anderson DP, Rumsey GL (1994) Dietary intake of immune stimulants by rainbow trout affects non-specific immunity and protection against furunculosis. Vet Immunol Immunopathol 41: 125-139.

2. Lara-Flores M, Olvera-Novoa MA, Guzman-Mendez BE, Lopez-Madrid W (2003) Use of the bacteria Streptococcus faecium and Lactobacillus acid ophilus, and the yeast Saccharomy cescerevisiae as growth promoters in Nile tilapia (Oreochromis niloticus). Aquaculture 216: 193-201.

3. Abdel-Tawwab M, Abdel-Rahman AM, Ismael N (2008) Evaluation of commercial live baker's yeast, Saccharomy cescerevisiae as a growth and immunity promote for fry Nile tilapia, Oreochromis niloticus (L.) challenged in situ with Aeromonas hydrophila. Aquaculture 280: 185-189.

4. He S, Zhou Z, Meng K, Zhao H, Yao B, et al. (2011) Effects of dietary antibiotic growth promoter and Saccharomyces cerevisiae fermentation product on production, intestinal bacterial community, and nonspecific immunity of hybrid tilapia (Oreochromis niloticus female $\times$ Oreochromis aureus male). J Anim Sci 89: 84-82.

5. Eshak MG, Khalil WBK, Hegazy EM, Farage IM, Fadel M, et al. (2010) Effect of yeast (Saccharomyces cerevisiae) on reduction of aflatoxicosis, enhancement of growth performance and expression of neural and gonadal genes in Japanese quail. J America Sci 6: 824-838

6. Xue M, Cui YB (2001) Effect of several feeding stimulants on diet preference by juvenile gibel carp (Carassius auratus gibelio), fed diets with or without partial replacement of fishmeal by meat and bone meal. Aquaculture 198: 281-292.

7. Ringø E, Birkbeck TH (1999) Intestinal microflora of fish larvae and fry. Aquacul Res 30: 73-93

8. Celli J, Knodler LA (2008) Of microbes and membranes: pathogenic subversion of host cell process. Cell Host Microbe 4: 514-518.

9. He S, Zhou Z, Liu Y, Cao Y, Meng K, et al. (2010) Effects of the antibiotic growth promoters flavomycin and florfenicol on the autochthonous intestinal microbiota of hybrid tilapia (Oreochromis niloticus 9 x O. aureus ${ }^{2}$ ). Arch Microbiol 192 985-994.

10. AOAC (1995) Official Methods of Analysis of the Association of Analytical Chemistry, 16 the dn. AOAC, Washington, DC.

11. He SX, Zhou ZG, Liu YC, Shi PJ, Yao B, et al. (2009) Effects of dietary Saccharomyces cerevisiae fermentation product (DVAQUA ${ }^{\circledR}$ ) on growth performance, intestinal autochthonous bacterial community and non-specific immunity of hybrid tilapia (Oreochromis niloticus $+\times 0$. aureus ${ }^{3}$ ) cultured in cages. Aquaculture 294: 99-107.

12. Liu Y, Zhou Z, Yao B, Shi P, He S, et al. (2008) Effect of intraperitoneal injection of immunostimulatory substances on allochthonous gut microbiota of Atlantic salmon (Salmo salar L.) determined using denaturing gradient gel electrophoresis. Aquacul Res 39: 635-646.

13. Abdel-Tawwab M, Abdel-Rahman AM, Ismael N (2008) Evaluation of commercial live baker's yeast, Saccharomces cerevisiae as a growth and immunity promoter for Fry Nile tilapia, Oreochromis niloticus (L.) challenged in situ with Aeromonas hydrophila. Aquaculture 280: 185-189.

14. Pooramini M, Kamali A, Hajimoradloo A, Alizadeh M, Ghorbani R (2009) Effect of using yeast (Saccharomyces cerevisiae) as probiotic on growth parameters, survival and carcass quality in rainbow trout Oncorhynchus mykiss fry. Int Aquat Res 1: 39-44.

15. Li P, GatlinlII DM (2003) Evaluation of brewer's yeast (Saccharomyces cerevisiae) as a feed supplement for hybrids triped bass (Moronechry sops $\times$ M. saxatilis). Aquaculture 219: 681-692.

16. Ye JD, Wang K, Li FD, Sun YZ (2011) Single or combined effects of fructoand mannan oligosaccharide supplements and Bacillus clausii on the growth feed utilization, body composition, digestive enzyme activity, innate immune response and lipid metabolism of the Japanese flounder Paralichthys olivaceus. Aquacul Nutr 17: e902-e911.

17. Ahilan B, Shine G, Santhanam R (2004) Influence of probiotics on the growth and gut microbial load of juvenile gold fish (Carassiu sauratus). Asian Fish Sci 17: $271-278$

18. Hoseinifar HS, Mirvaghefi A, Merrifield DL (2011) The effects of dietary inactive brewer's yeast Saccharomyces cerevisiae var. ellipsoideus on the growth, physiological responses and gut microbiota of juvenile beluga (Huso huso) Aquaculture 318: 90-94. 
Citation: He S,Wan Q,Ren P, Yang Y, Yao F, et al. (2011) The Effect of Dietary Saccharoculture on Growth Performance, Non-Specific Immunity and Autochthonous Gut Microbiota of Gibel Carp Carassius auratus. J Aquac Res Development S1:010. doi:10.4172/2155-9546.S1-010

Page 6 of 6

19. Rumsey GL, Winfree RA, Hughes SG (1992) Nutritional values of dietary nucleic acids and purine bases to rainbow trout. Aquaculture 108: 97-110.

20. Engstad RE, Robertsen B, Frivold (1992) Yeast glucan induces increase in lysozyme and complement-mediated haemolytic activity in Atlantic salmon blood. Fish Shell fish Immunol 2: 287-297.

21. Raa J, Rorstad G, Engstad R, Robersten B (1992) The use of immune stimulants to increase resistance of aquatic organisms to microbial infections. In: Diseases in Asian Aquaculture (I.M. Shariff, R.P. Subasingle and J.R. Arthurs, eds). Fish Health Section, Asian Fisheries Society, Manila, Philippines, pp. 39- 50 .

22. Raa J (1996) The use of immunostimulatory substances in fish and shellfish farming. Rev Fisheries Sci 4: 229-288.

23. Esteban MA, Cuesta A, Ortuňo J, Meseguer J (2001) Immunomodulatory effects of dietary intake of chitin on gilthead seabream (Sparusaurata L.) innate immune system. Fish Shellfish Immunol 11: 303-315.

24. Sakai DK (1992) Repertoire of complement in immunological defense mechanisms of fish. Ann Rev Fish Dis 223-247.

25. Matsushita M, Endo Y, Nonaka M, Fujita T (1998) Complement-related serine proteases in tunicates and vertebrates. Curr Opin Immunol 10: 29-35.

26. Sunyer JO, Lambris JD (1998) Evolution and diversity of the complement system of poikilothermic vertebrates. Immunol Rev 166: 39-57.

27. Raa J (2000) The use of immuno - stimulants in fish and shellfish feeds. In: Avances en Nutricion Acucola $V$ Memorias del $V$ Simposium Int de Nutricion Acucola.

28. Zhou XQ, Li YL (2004) The effect of Bio-Mos ${ }^{\circledR}$ on intestinal microflora and immune function of juvenile Jian carp (Cyprinus carpio Var. Jian). In: Nutritional Biotechnology in the Feed and Food Industries, Proceedings of Alltech's 20th Annual Symposium.
29. Ringø E, Strøm E (1994) Microflora of Arctic charr, Salvelinus alpinus (L.): gastrointestinal microflora of free-living fish and effect of diet and salinity on intestinal microflora. Aquacul Res 25: 623-629.

30. Kang BR, Lee JH, Ko SJ, Lee YH, Cha JS, et al. (2004) Degradation of acylhomoserine lactone molecules by Acinetobacter sp. strain C1010. Can J Microbiol 50: 935-941.

31. Perdigon G, Galdeano C, Valdez J, Medici M (2002) Interaction of lactic acid bacteria with the gut immune system. Eur J Cli Nutr 56: 21-26.

32. Ringø E, Bendiksen HR, Gausen SJ, Sundsfjord A, Olsen RE (1998) The effect of dietary fatty acids on lactic acid bacteria associated with the epithelial mucosa and from faecalia of Arcticcharr, Salvelinusal pinus L. J Appl Microbiol 85: 855-864

33. Aly SM, Ahmed YA, Ghareeb AA, Mohamed MF (2008) Studies on Bacillus subtilis and Lactobacillus acidophilus, as potential probiotics, on the immune response and resistance of Tilapia nilotica (Oreochromis niloticus) to challenge infections. Fish Shellfish Immunol 25: 128-136.

34. Hoseinifar SH, Mirvaghefi A, Meffifield DL (2011) The effects of dietary inactive brewer's yeast Saccharomyces cerevisiae var. ellipsoideus on the growth, physiological response and gut microbiota of juvenile beluga (Huso huso) Aquaculture 318: 90-94.

35. Tsuchiya C, Sakata T, Sugita $H$ (2008) Novel ecological niche of , an anaerobic bacterium in the intestinal tracts of freshwater fish. Lett Appl Microbiol 46: 4348.

36. Butaye P, Devriese LA, Haesebrouck F (2003) Antimicrobial growth promoters used in animal feed: effects of less well known antibiotics on gram-positive bacteria. Clin Microbiol Rev 16: 175-188.
This article was originally published in a special issue, Probiotic \& Prebiotic Applications in Aquaculture handled by Editor(s). Dr. Daniel L. Merrifield, University of Plymouth, UK; Prof. Zhigang Zhou, Chinese Academy of Agricultural Sciences, China 